\title{
Mapping the Issues
}

\section{Introduction}

Samantha Besson*

\section{The General Issue}

$\mathrm{U}$ ntil recently, the question of human rights in science had by and large been neglected by international human rights lawyers and international human rights institutions alike. It was once even referred to, very tellingly, as the "sleeping beauty" of international human rights law. ${ }^{1}$

Because international human rights lawyers have not yet focused on the issue much, discussions that have taken place in other fora have barely scratched the surface. They have often glossed over the freedom of scientists, ${ }^{2}$ neglecting the concurring rights of everyone else to benefit from scientific progress, but also the other moral considerations in light of which the rights of scientists may have to be restricted including other human rights - except maybe for intellectual property rights that have attracted a lot of attention in recent years. ${ }^{3}$ Additionally, debates have been mostly concerned with the human rights of scientists abroad, rather than at home, and usually in failed or dictatorial states. ${ }^{4}$ They have also understated the concurrent human rights duties and/or responsibilities of other states, international organizations and private actors such as corporations but also private or semi-public research institutions. Finally, discussions have mostly focused on natural sciences, leaving the more subtle albeit sometimes more complex questions of human rights in human and social sciences aside.

\footnotetext{
* Many thanks are due to Odile Ammann for her assistance with the editing of this introduction and to Gaelle Mieli for her assistance with the editing of the other contributions in this special issue. Thanks also to Olivier De Schutter for hosting this special issue in his journal and to all anonymous reviewers for their comments and critiques.

1 See E. RIEDEL, "Sleeping Beauty or Let Sleeping Dogs Lie? The Right of Everyone to Enjoy the Benefits of Scientific Progress and its Applications (REBSPA)", in H. Hestermeyer et al. (eds), Coexistence, Cooperation and Solidarity, Liber Amicorum Rüdiger Wolfrum, Leiden, Nijhoff, 2011, p. 503.

2 There is a propensity to still identify many of the rights and duties related to the human right to science to the moral rights and duties of scientists that stem from science itself as a normative practice. See e.g. AAAS Science and Human Rights Coalition, "Defining the Right to Enjoy the Benefits of Scientific Progress and its Applications: American Scientists' Perspectives", Report prepared by Margaret Weigers Vitullo and Jessica Wyndham (October 2013).

${ }^{3}$ See e.g. L. Helfer and G.W. Austin, Human Rights and Intellectual Property: Mapping the Global Interface, Cambridge, Cambridge University Press, 2011, pp. 233-242; A. Plomer, "The Human Rights Paradox: Intellectual Property Rights and Rights of Access to Science", Human Rights Quarterly, vol. 35, nº 1, 2013, p. 143; C. TimmerMANN, "Sharing in or Benefiting from Scientific Advancement?", Sci Eng Ethics, vol. 20, no 1, 2014, p. 111, at p. 125-127. See also, most recently, L. ShAVER, "The Impact of Intellectual Property Regimes on the Right to Science and Culture", Background note submitted to the Special Rapporteur in the field of cultural rights Ms. Farida Shaheed (20 May 2014); Report of the Special Rapporteur in the field of cultural rights Ms. Farida Shaheed on copyright policy and the right to science and culture, presented at the twenty-eight session of the Human Rights Council (24 December 2014) (A/HRC/28/57).

${ }^{4}$ See e.g. the work done in the context of the International Human Rights Network of Academies and Scholarly Societies.
} 
Prima facie, this state of affairs is very surprising as human rights in the scientific context have been guaranteed in international human rights instruments since the 1940s. Things have recently started to change, however. The interest in what is now commonly called the "Human Right to Science"5 as shorthand for the "Right to enjoy the benefits of scientific progress and its applications" (REBSPA; Article 15(1)(b) International Covenant on Economic, Social and Cultural Rights $[\mathrm{ICESCR}]^{6}$ ) is rising. So, one may say that the human right to science is at once an old right and a new topic.

First of all, the human right to science is an old right in international human rights law. It was guaranteed, first, by Article 27 of the Universal Declaration of Human Rights (1948) and, more recently, by Article 15(1)(b) ICESCR (1966). It is also a right that has long been protected in regional and domestic instruments, ${ }^{7}$ and in various UN (e.g. 1975) and UNESCO (e.g. 1974 and 2005) declarations and statements on biotechnology and human rights in particular. ${ }^{8}$

A first reason one may venture for the neglect of the right both in practice (e.g. there has been no or very little State reporting and international monitoring on that right) and scholarship, however, pertains to the meaning of science itself and the difficulty to define it. This indeterminacy and the controversies surrounding it have actually had a chilling effect on the practice of the right to science, ${ }^{9}$ including its monitoring by the Committee on Social, Economic and Cultural Rights [CESCR $].{ }^{10}$ Secondly, science and technology are "inextricably linked" with the means of protection of other human rights ${ }^{11}$ (see e.g. Article 2(1) and 23 ICESCR

\footnotetext{
${ }^{5}$ See for this expression, e.g. Report of the Special Rapporteur in the field of cultural rights Ms. Farida Shaheed on the right to enjoy the benefits of scientific progress and its applications, presented at the twentieth session of the Human Rights Council (14 May 2012) (A/HRC/20/26), p. 3; P. SAUL, D. Kinley, and J.F. Mowbray, "Art. 15 : Cultural Rights", in B. SAUL, D. KInLEy, and J.F. MowbraY, The International Covenant on Economic, Social and Cultural Rights: Commentary, Cases and Materials, Oxford, Oxford University Press, 2014, p. 1175, at p. 1212; J. RingeLHEIM, "Cultural Rights", in D. Moeckli, S. ShaH, and S. Sivakumaran (eds), International Human Rights Law, $2^{\text {nd }}$ edition, Oxford, Oxford University Press, 2013, p. 286, at p. 296-297.

${ }^{6}$ Most of the contributions in this special issue focus on Article 15(1)(b) ICESCR only, but it is important to realize that this (mainstream) choice of source of the right to science affects their approach to the right.

7 See e.g. Report of the Special Rapporteur on the right to enjoy the benefits of scientific progress and its applications, op. cit.; and B. SAUL, D. KInLEY, and J.F. MowbraY, "Art. 15: Cultural Rights", op. cit., for a full survey of those domestic and regional instruments.

${ }^{8}$ See e.g. UN Declaration on the Use of Scientific and Technological Progress in the Interests of Peace and for the Benefit of Mankind, Proclaimed by UN General Assembly, Resolution 3384 (XXX) (10 November 1975) (A/ RES/30/3384); UNESCO, Recommendation on the Status of Scientific Researchers (20 November 1974); UNESCO Universal Declaration on Bioethics and Human Rights (19 October 2005).

9 See e.g. A. ChAPMAn, "Towards an Understanding of the Right to Enjoy the Benefits of Scientific Progress and Its Applications", Journal of Human Rights, vol. 8, n 1, 2009, p. 1; A. MülLER, "Remarks on the Venice Statement on the Right to Enjoy the Benefits of Scientific Progress and its Applications (Article 15(1)(b) ICESCR)", Human Rights Law Review, vol. $10, \mathrm{n}^{\circ} 4,2010$, p. 765 , at p. 766 .

${ }_{10}$ There are very few traces of the right in the practice of the CESCR and when there are, they are very brief. See e.g. CESCR, Report on the $7^{\text {th }}$ Session $(23$ November-11 December 1992) (E/1993/22), § 73 (Belarus).

11 See e.g. B. SAul, D. Kinley, and J.F. Mowbray, “Art. 15: Cultural Rights", op. cit., pp. 1223-1224; Report of the Special Rapporteur on the right to enjoy the benefits of scientific progress and its applications, op. cit., pp. 8, 16-23; UNESCO, Venice Statement on the Right to Enjoy the Benefits of Scientific Progress and its Applications (Article 15(1)(b) ICESCR) (16-17 July 2009), at 12(d). See also W.A. SchABAS, "Study of the Right to Enjoy the Benefits of Scientific and Technological Progress and its Applications", in Y. DONDERS and V. VolODIN (eds), Human Rights in Education, Science, and Culture: Legal Developments and Challenges, Aldershot, Ashgate, 2008, p. 273, at p. 302; TimmermanN, "Sharing in or Benefiting from Scientific Advancement?", op. cit., pp. 125-127.
} 
in general; Article 11(2) ICESCR with respect to the right to food ${ }^{12}$ ). Most of their protection by international human rights law has occurred through those other channels, therefore.

Secondly, and at the same time, the human right to science also amounts to a new topic since practical and academic interest for the right has increased recently. ${ }^{13}$ This has been the case both at UNESCO with the 2009 Venice Statement ${ }^{14}$ and, more recently, at the UN. Thus, on 14 May 2012 the UN Special Rapporteur in the field of cultural rights published a report on the meaning and application of the right to enjoy the benefits of scientific progress and its applications (Article 15(1) (b) ICESCR). ${ }^{15}$ On 3-4 October 2013, a two-day seminar was organized by the Office of the High Commissioner for Human Rights in Geneva to discuss the meaning and application of the human right to science. The goal now is for the CESCR to publish recommendations and prepare a General Comment on how to implement the human right to science (Article 15(1)(a) and (c) already have General Comments 17 and 21). The Special Rapporteur has since then led another consultation on the impact of intellectual property regimes on the enjoyment of the rights to science and culture. On that basis, she published a first report on copyright policy and the right to science and culture on 24 December $2014^{16}$ and will present a second one on patent policy and the right to science and culture in 2015. Finally, in July 2014, the UNESCO decided to launch an open consultation to guide the revision of their 1974 Recommendation on the Status of Scientific Researchers.

There are various reasons one may venture for this renewed interest in the human right to science. And to mention just a few here: heightened sensitivity for global justice and equality, and hence stronger reactions to the technological divide and innovation injustices that have caused great poverty, famine and illness in some parts of the world; $;^{17}$ greater technological capacities, and new linkages being

\footnotetext{
12 On the right to science and the right to food, see e.g. O. De Schutter, "The Right of Everyone to Enjoy the Benefits of Scientific Progress and the Right to Food: From Conflict to Complementarity", Human Rights Quarterly, vol. 33, $\mathrm{n}^{\circ}$ 2, 2011, p. 304; H.M. HAUGEN, "Human Rights and Technology: A Conflictual Relationship? Assessing Private Research and the Right to Adequate Food", Journal of Human Rights, vol. 7, n 3, 2008, p. 224. On the right to science and the right to health, see e.g. Y. DonDERs, "The Right to Enjoy the Benefits of Scientific Progress: In Search of State Obligations in Relation to Health", Medicine, Health Care and Philosophy, vol. 14, $\mathrm{n}^{\circ} 4,2011$, p. 371; S.P. MARKs, "Out of Obscurity: The Right to Benefit from Advances in Science and Technology and Its Implications for Global Health", Proceedings of the $3^{\text {rd }}$ Conference on Law, Science and Technology: Health and Science - Human Rights and Legal Issues, Taipei 2012, p. 1.

${ }_{13}$ See e.g. A. Chapman and J. Wyndham, "A Human Right to Science", Science, vol. 340, n 6138, 2013, p. 1291; MÜLLER, "Remarks on the Venice Statement", op. cit.; L. SHAVER, "The Right to Science and Culture", Wisconsin Law Review, n 1, 2010, p. 121; A. ChAPMAN, "Towards an Understanding", op. cit.; W.A. SchABAs, "Study of the Right to Enjoy the Benefits of Scientific and Technological Progress and its Applications", op. cit.; R.P. CLAUDE, "Scientists' Rights and the Human Right to the Benefits of Science", in A. CHAPMAN and S. Russell (eds), Core Obligations: Building A Framework for Economic, Social and Cultural Rights, Antwerp, Oxford, and New York, Intersentia, 2002, p. 247.

14 Venice Statement 2009, op. cit.

15 Report of the Special Rapporteur on the right to enjoy the benefits of scientific progress and its applications, op. cit.

op. Report of the Special Rapporteur on copyright policy and the right to science and culture, op. cit.
${ }_{16}$.

17 See e.g. T. POGGE, "The Health Impact Fund: Enhancing Justice and Efficiency in Global Health", Journal of Human Development and Capabilities, vol. 13, n ${ }^{\circ}$ 4, 2012, p. 537; A. Buchanan, T. Cole, and R.O. Keohane, "Justice in the Diffusion of Innovation", The Journal of Political Philosophy, vol. 19, n 3, 2011, p. 306.
} 
made between science and technology; greater sensitivity to the power of private actors including corporate actors and new legal tools to curtail those threats, especially in the context of social, economic and cultural rights $;^{18}$ and greater institutional capacity at the international level, and means to cooperate internationally as a result.

Whatever the reasons for this renewed interest, the human right to science also offers interesting features that may be of interest to any scholar in international human rights law and theory. First of all, the dual holdership of the right. Because it is a right held both by scientists and by everyone else at the same time, it cannot be protected like any other right. ${ }^{19}$ This also has consequences for the resolution of what may at first seem like conflicts of rights, but may not be. ${ }^{20}$ Secondly, the complexity of science as object of a human right. The difficulty to define it and its relationship to other related endeavours and notions such as innovation or progress makes for a very indeterminate right. One should also mention the complex ties between science, moral and social progress, economic prosperity and democratic legitimacy, and the potential advantages and disadvantages in this context of conceiving of science in human rights terms. ${ }^{21}$ Thirdly, the interest protected by the right pertains to a global public good, and hence is such that it can only be effectively protected if all its duty-bearers coordinate in fulfilling their collective duties. This makes for interesting prospects in terms of the supply-side of the right and devising actual duties of international cooperation between the various duty-bearers of the right to science. ${ }^{22}$ Fourthly, Article 15(1) ICESCR protects the right to access the benefits of science (b)) together with the moral and material interests of the author resulting from the scientific production of those benefits (c)). This dual object of the right to science, i.e. "access" of everyone and "protection" of the author, provides for a promising framework to alleviate the alleged tensions between the human right to science and intellectual property regimes. ${ }^{23}$ Finally, one should mention the basic nature of the human right to science and the necessity of its implementation for the respect of many other human rights, such as the right to health or to food. This has interesting consequences for the stringency of the corresponding duties and their relationship to other rights' duties that may not be as conflictual as they seem to be at first. ${ }^{24}$

\footnotetext{
${ }^{18}$ See e.g. O. De Schutter, International Human Rights Law, $2^{\text {nd }}$ edition, Cambridge, Cambridge University Press, 2014, p. 187 ff.; M. LANGFORD et al. (eds), Global Justice, State Duties - The Extraterritorial Scope of Economic, Social, and Cultural Rights in International Law, Cambridge, Cambridge University Press, 2012.

19 See e.g. W.A. SchABAS in this volume.

20 See e.g. J. WYNDHAM and Y. DONDERS in this volume.

${ }^{21}$ See e.g. W.A. SchabAS in this volume.

22 See e.g. S. BESSON in this volume.

${ }^{23}$ See e.g. L. SHAVER in this volume.

24 See e.g. Y. DONDERS and L. SHAVER in this volume.
} 


\section{This Special Issue}

In the wake of this renewed interest for human rights in science and in view of the difficult issues the topic raises, the University of Fribourg and the Chair for Public International Law and European Law decided to pursue the debate in a small scientific setting and organized a workshop on the topic on 23-24 May 2014. The workshop was organized with the financial support of the Swiss National Science Foundation and the Public International Law Directorate of the Swiss Department of Foreign Affairs.

This workshop brought together a group of academic human rights lawyers and human rights theorists specialized in the field and interested in delving deeper into some of its hard questions. By drawing in both international lawyers and philosophers, the hope was to map and address those questions in a more comprehensive fashion and to suggest ways of guiding and reforming the current practice and institutional framework of human rights in science. The small, intimate and informal setting allowed for longer and freer exchanges than in more politicized national and international frameworks. Discussions further benefited from the participation of three general discussants: Mylène Bidault from the Office of the High Commissioner for Human Rights; Amrei Müller from the University of Oslo; and Olivier De Schutter from the Catholic University of Louvain and the Committee on Economic, Social and Cultural Rights. Last but not least, Allen Buchanan from Duke University and King's College, London presented a paper at the workshop that is not published in this special issue: Justice in Innovation and Human Rights in and to Science.

The workshop was organized around seven questions:

1) Which are the human rights that apply in the field of science (e.g. is there a "human right" to "science" and what could it mean? How do some of them differ from the moral and legal rights of creators and intellectual property rights in particular?), and what are their objects (e.g. what are the interests protected? How do they relate?) and their potential linkages (e.g. are some more basic than others?)?

2) What are the (individual or social) justifications or grounds for the human rights that apply to science and how do they relate to other rights' justifications or grounds and are they sufficiently universal?

3) What is the content of the human rights that apply in the field of science, what kind of (positive or negative; substantive and procedural; immediate or progressive; minimal or maximal) duties do they give rise to and what is their (material) scope?

4) Who are the (individual or collective) subjects of human rights in the field of science? 
5) Who are the corresponding (individual or institutional; territorial or extraterritorial) duty-bearers and responsibility-bearers, and what are their relationships?

6) How should one resolve human rights "conflicts" (e.g. with the right to food, the right to health, the right to education, the freedom of speech, the right to property, etc., but also within the "human right to science" itself [e.g. Article 15(1)(b) ICESCR's right to enjoy the benefits of scientific progress and 15(1)(c) ICESCR's right to the protection of the moral and material interests resulting from scientific authorship]) and conflicts of human rights in the field of science with other (non-human rights-based) moral and legal considerations (e.g. intellectual property and other similar moral rights)?

7) How should one implement human rights effectively in the field of science (e.g. judicially or not; globally or not), and how may one justify their restrictions?

Most of those questions are addressed by the five articles presented in this special issue. Here is a brief survey of the content of those contributions and their articulation.

In her article The Right to Science: Everyone Benefits from Scientific and Technological Progress, Lea Shaver (Indiana University McKinney School of Law) contends that the right to enjoy the benefits of scientific progress and its applications has long been neglected, both in theory and in practice. Even scholars, advocates, and jurists deeply involved in the human rights field are likely to express uncertainty as to what the right to science concretely requires, if they are even aware of its existence. She seeks to remedy that obscurity, providing a highly accessible account of the right to science that is both philosophically grounded and very practical. In short, the right to science calls for treating science and technology as global public goods, to be cultivated for the benefit of humanity and made accessible to all, just as with other socioeconomic rights such as education and healthcare. She then elaborates what that broad vision means for minimum core content. Particular emphasis is given to reconciling the potential tension between the right to science and intellectual property regimes.

In their contribution The Right to Science: Whose Right? To What?, Jessica Wyndham (American Association for the Advancement of Science and George Washington University) and Margaret Weigers Vitullo (American Sociological Association) write about the meaning of the right to enjoy the benefits of scientific progress and its application, as well other corresponding duties set out in Article 15 of the International Covenant on Economic, Social and Cultural. Focusing on the three pillars of the right - access, participation and protection their contribution is to build on existing literature by introducing the perspectives of the scientific community, both as specifically elicited through a multi-disciplinary focus group process involving US-based scientists, and as reflected in parallel debates and discussions occurring within the scientific community as they bear on the right to science. 
In her article Science Without Borders and the Boundaries of Human Rights: Who Owes the Human Right to Science?, Samantha Besson (University of Fribourg \& Human Rights Delegate of the Swiss Academies of Arts and Sciences) contends that what is specific about the supply-side or duty-side of the right to science is two-fold. First of all, by virtue of the interest protected by the right to science, i.e. the access to the benefits of science and hence an individual interest in a universal public good, and of the universal scope of the threats to that interest, the duties relative to the right to science are collective duties States and/or international institutions of jurisdiction bear together, and not only concurrently. This has consequences for their feasibility and hence for their recognition in the first place, but also for their co-allocation among States and institutions of jurisdiction and not only within each of them. Secondly, this also has an impact on the other private actors', States' and international institutions' responsibilities for the right to science, since those responsibilities are borne together as well and should, as a result, be coordinated in their primary allocation. In short, the "unbounded" nature of science should not be too quickly defeated by the "bounded" nature of human rights. If the human right to science and hence to innovation is to be protected effectively, one should be ready to innovate institutionally in order to "unbound" their corresponding duties and responsibilities.

In her contribution Balancing Interests: Limitations to the Right to Enjoy the Benefits of Scientific Progress and Its Applications, Yvonne Donders (University of Amsterdam) contends that while several studies and reports have been elaborated on the normative content and state obligations of the right to enjoy the benefits of scientific progress and its applications, one of the legal aspects that has not yet been fully explored are the possible limitations of this right. The right to enjoy the benefits of scientific progress is, just as most other human rights in international law, not absolute. States may, under certain circumstances, limit the enjoyment of human rights. For instance, States may or even must limit the conduct of science or the dissemination of scientific results in order to prevent harm or disrespect of other human rights. Her contribution analyses the legal framework of limitations of the right to enjoy the benefits of scientific progress, based on the different regimes in international human rights law. In international human rights law, the possibility of and criteria for limitations are laid down in treaty provisions, so-called limitation clauses. The scope of these clauses has been elaborated by international supervisory bodies and academics. Limitations form part of the more general doctrine of State obligations, which in the case of the right to enjoy the benefits of scientific progress is characterized by the ICESCR regime of progressive realisation of this right and the prohibition of retrogressive measures.

In his contribution Looking Back: How the Founders Considered Science and Progress in their Relation to Human Rights, William A. Schabas (University of Middlesex, London and University of Leiden) contends that Article 27 of the Universal Declaration of Human Rights enshrines the right of everyone to share in scien- 
tific advancement. The word "advancement" may imply a value judgment on the content of science. However, the drafting history of the Declaration shows that a more robust effort to frame and define the nature of science, promoted by the Soviet Union and some of its allies, was not successful. This is in contrast with a similar and more successful effort in Article 26 which concerns the right to education. The paper analyses the travaux préparatoires of the Universal Declaration. These materials are inconclusive, although subsequent application and interpretation of Article 27 lends support to the view that its interpretation is not entirely neutral as far as the direction and content of scientific research are concerned.

\section{Samantha Besson}

is Professor of Public International Law and European Law at the University of Fribourg, Switzerland \& Human Rights Delegate of the Swiss Academies of Arts and Sciences. She can be reached at: samantha.besson@unifr.ch. 